DOI 10.37882/2223-2982.2021.12.18

\title{
ИССЛЕДОВАНИЕ ТОПОНИМОВ КАЗАХСКОГО И АНГЛИЙСКОГО ЯЗЫКОВ В КОГНИТИВНОМ НАПРАВЛЕНИИ'
}

\section{RESEARCH OF THE TOPONYMS OF THE KAZAKH AND ENGLISH LANGUAGES IN THE COGNITIVE DIRECTION}

\section{A. Meirbekov}

Summary: This article examines the study of Kazakh and English toponyms in the context of cognitive linguistics, cognitive structures and processes associated with a person, that is, the mechanisms of systematic description of toponyms and clarification of human perception of language and the principles of constructing these mechanisms. Toponymic vocabulary of any language is an internally organized and regulated system. The study of this subsystem of the language is of great importance both for onomastics and for linguistics in general. The anthropocentric direction in the study of toponymic vocabulary, aimed at the study of units of the toponymic system in close connection with human thinking and spiritual and practical activity, is promising, since it allows you to study the system as a product of human cognitive activity. In the course of the study, methods of description, classification, generalization, analysis were used to determine the etymology of the region's anthropotoponyms. The etymological origin of anthropotoponymic names is described, and the linguistic significance of the word-formation process is determined by classification and generalization. Toponyms are analyzed as a speech expression processed in consciousness, a linguistic image of the world - the relationship between a person and the environment. The modern stage of toponyms in cognitive research includes the consideration of language as one of the cognitive subsystems and onomastic vocabulary in the formulation of surrounding truths. As part of national toponymic images of the world, it is considered as an object of study of the regional (regional) toponymic image.

Keywords: cognitive linguistics, toponym, onomastics, Kazakh, English.

\author{
Мейрбеков Акылбек Кайратбекович \\ Д.филол.н., и.о. доцента, Международный казахско- \\ турецкий университет имени Ходжи Ахмеда Ясави, \\ Туркестан, Казахстан \\ ph-doctor@mail.ru
}

Аннотация: В данной статье рассматривается изучение казахских и английских топонимов в контексте когнитивной лингвистики, когнитивных структур и процессов, связанных с человеком. То есть объектом исследования являются механизмы систематического описания топонимов и разъяснения восприятия человеком языка, а также принципы построения этих механизмов. Топонимическая лексика любого языка - это внутренне организованная и регулируемая система. Её изучение имеет большое значение как для ономастики, так и для лингвистики в целом. Антропоцентрическое исследование топонимической лексики, направленное на изучение единиц топонимической системы в тесной связи с человеческим мышлением и духовно-практической деятельностью, является перспективным, так как позволяет изучать систему как продукт познавательной деятельности человека. В ходе исследования использовались методы описания, классификации, обобщения и анализа, необходимые для определения этимологии антропотопонимов региона. Описание позволяет понять этимологическое происхождение антропотопонимических названий, а лингвистическая значимость словообразовательного процесса определяется путем классификации и обобщения. Топонимы анализируются как речевое выражение языкового образа мира, обработанное сознанием, в отношении человека и окружающей среды. Современный этап топонимов в когнитивных исследованиях включает в себя рассмотрение языка как одной из их подсистем и ономастической лексики в формулировании общепринятых истин. Региональные топонимические образы, являются одним из многих объектов, в рамках исследований общенациональных топонимических образов.

Ключевые слова: когнитивный лингвистика, топоним, ономастика, казахский, английский.

ких катастроф и побед, потому что само место является ярким свидетельством всех этих событий. Они рисуют картину прошлого и связывают его с настоящим. Это позволяет визуализировать прошлые события через названия мест. Большинство топонимов основаны на желании номинатора создать осознание всеми членами общества привязанность названия к определённой местности.

Очевидно, что географические названия или топонимы, имеющие это особое значение, рассказывают об на карте. Для носителей языка, людей, которые жили здесь сотни лет, оно ассоциируется с историей велилексике каждого языка мира, в связи с чем всестороннее их рассмотрение является просто необходимым.

Географическое название - это не просто надпись

$$
\text { - }
$$
зования и науки Республики Казахстан. 
истории поселения и верованиях его жителей или о людях, которые жили в этом поселении.

Лингвокультурология предоставляет информацию из истории одного или нескольких народов, то есть она также направлена на сравнение родства или сходства традиций одной этнической группы с другой. Другими словами, это имеет прямое отношение к признанию языковой природы топонимов как проявлений межкультурного и межъязыкового общения.

Программа этнолингвистики направляет исследователя на рассмотрение взаимосвязи между языком и духовной жизнью, национальным менталитетом, а также народным искусством [1].

«Современный этап ономастических исследований направлен на изучение языка как одной из когнитивных подсистем и ономастической лексики в формулировании окружающей действительности. Лингвокогнитивное направление исследований позволяет на концептуальном уровне исследовать особенности топонимов, в которых просматриваются мыслительные процессы формирования ономастических единиц в языке. [2]. Человек сознательно и избирательно воспринимает окружающую среду как часть природы и участвует в процессе выдвижения одного объекта с точки зрения интереса, заключающегося в его преобладании над другим. Осознанно выбирая тот или иной лингвистический инструмент, человек поражается разнообразию языка. [3].

Языковой образ мира - это лингвистическое отражение сознательно обработанной реальности взаимоотношений человека и окружающей среды. Образ мира, созданный с участием человеческого сознания, отражается во взаимодействии языковых единиц (лексика, грамматика, фразеология, тексты) и передается из поколения в поколение, т.е. через язык материализуется познание человеком мира, так что язык - это образ жизни. Существует три различных уровня мысленного отражения в формировании знаний о мире:

1. уровень чувственного восприятия;

2. уровень сформированности понимания (элементарное обобщение, формулировка и абстракция);

3. уровень языко-мыслительных процессов.

Методы исследования: в статье использованы методы описания, классификации, обобщения, сопостовительноесравнение топонимов двух языков. По результатам исследования составлено обобщение этимологического происхождениятопонимов казахского и английского языка.

Цель исследования: рассмотреть топонимические единицы казахского и английского языка, а также раскрытие их значения путем этимологического описания топонимов.

\section{Актуальность темы}

Топонимическая лексика любого языка - это внутренне организованная и регулируемая система. Изучение этой подсистемы имеет большое значение как для ономастики, так и для лингвистики в целом. Иследования, направленные на зучение единиц топонимической системы в тесной связи с человеческим мышлением и духовно-практической деятельностью, являются перспективными. Они позволяют изучать систему как продукт познавательной деятельности человека. Рассмотрение фонда топонимов в тесной связи с национальной историей, культурой, духовным богатством открывает путь к истинному пониманию природы топонимов страны. Учитывая роль и важность топонимов в познании мира посредством лингвистики, одной из наиболее актуальных проблем при сравнении казахского и английского языка, на сегодня является определение ментальных и когнитивных характеристик топонимических языковых единиц.

Таким образом, в сфере использования топонимической лексики наиболее перспективными и актуальными являются когнитивно-прагматические аспекты топонимической системы языка с учетом законов языковой номинации и человеческого мышления.

Когнитивная лингвистика фокусируется на изучении естественного языка, в котором язык понимается как средство организации, передачи и обработки информации, а также как форма когнитивных способностей человека. Формальная структура языка рассматривается как проявление законов категоризации и общей концептуальной организации.

Язык - это образ жизни и формирование познания человеком мира. В результате взаимодействия человека с окружающим миром формируются знания о мире, и создаётся его модель. Образ мира - одно из основополагающих понятий, характеризующих человеческую природу. В последнее десятилетие в когнитивной лингвистике поднимается вопрос об отражении в сознании человека единого образа мира, зафиксированного в языке.

Можно сказать, что в современной когнитивной лингвистике лингвистический образ мира исследуется довольно интенсивно. Понятие или категория «языковой образ мира» связано с такимими категориями и терминами как познание мировоззрения в отношении языкового (этнического) сознания. По мнению русского ученого Г.В. Колшанского, нельзя говорить о «языковом образе мира», отдельно от «языкового сознания», так как эти понятия связаны напрямую. [4].

Связь и целостность языка, а также познания (мировоззрение, этническое познание) отражаются не только 
в «языковом образе мира», выраженном в нарицательных существительных, но и в «образе ономастической вселенной». Оная рассматривается в трудах Б.М. Тлеубердиева. Б.М. По словам Тлеубериева: «Топонимический взгляд на мир следует рассматривать с точки зрения языкового осознания местного населения. Представление о пространстве в языковом сознании формировалось в разные исторические эпохи. Существует система ментальных принципов, когнитивных концепций, отраженных в ту эпоху [6].

Прежде чем рассматривать проявления познания этноса в топонимической системе, необходимо определить такие понятия (категории), как познание (самого этноса или познание ментальноси народности), мировоззрение, а также региональный топонимический образ мира.

Лингвистический образ мира, сформированный в сознании и языке любого народа, является результатом и проявлением познания этноса, только потому, что он находит своё место в сознании и языке определённой этнической группы Познание, в целом, философская категория, основные характеристики которой следующие: психологический и эстетический подход к окружающей среде. Результаты познания мира отражаются в понятии «мировоззрение, которое является результатом совокупности представлений индивида о своем месте в обществе и понимании мира в целом» [7].

Мировоззрение носит этнический характер, поскольку является продуктом этого самого этноса и имеет определённые корни. Следует отметить и этнокультурные факторы, формирующие характеристики мировоззрения. Языковой образ мира всегда является результатом этнического познания и выражается лингвически. Представлен народа о мире формируются применительно к мировоззрению этого народа и отражаются в его языке. В связи с этим, когда мы говорим о лингвистическом образе мироздания, мы должны говорить об особенностях различных этносов вселенной.

Национальный (этнический) языковой образ мира это многогранная, многокомпонентная, иерархическая система или структура. Если рассматривать национальный (этнический) языковой образ мира как некий инвариант, то следует отметить, что в систему входят социальные, индивидуальные, ономастические, региональные и другие компоненты.

Например, ономастический национальный образ мира является частью (компонентом) общенационального образа мира, и этот языковой образ распознается, создается, формируется на уровне личных имен. Как указывает Б.М. Тлеубердиев: «Если языковой образ мира отражает национальный образ мира в языковых единицах разного уровня, то логично сказать, что единичные имена на ономастическом уровне являются фрагментом национального языкового образа мира. мира и может формировать ономастический национальный образ мира».

Б.М. Тилеубердиев дал определение ономастическому национальному образу мира и отметил его связь с этническим познанием. «Ономастический (национальный) образ мира» мы называем систематическим и сложным набором аналогичных понятий и лингвистическим выражением национального познания на уровне личных имен. Жизнь, быт, хозяйство, менталитет, эстетические вкусы, мифологические, религиозные, этнические концепции, социальный опыт нации или отдельного человека оставляют неизгладимый след на «зеркале языка», т.е. в лексике, фразеологии - существительных общего и единственного числа. Каждый из «следов» символизирует не только этническияе среды, но и познание. Ономастический образ этнокогнитивного мира, в свою очередь, делится на несколько образов подмиров: мифологический (внутреннего мира), антропонимический и топонимический [6].

Ономастический образ мира, как отмечалось выше, является составной частью, т. е. фрагментом языкового образа мира, а топонимический является неотъемлемой частью последнего.

В рамках национального топонимического образа мира мы можем рассматривать региональный топонимический образ как объект исследования, поскольку он является лингвистически-ментальным выражением определенного культурно-исторического региона на уровне топонимов и микротопонимов. Таким образом, в региональной топонимической системе вербализируются этнокогнитивные (мировоззренческие) особенности страны и народов, проживающих в каждом отдельно взятом регионе с древнейших времен.

Если рассматривать региональную топонимию с ментально-когнитивной точки зрения, то типы познания (мировоззрения) образуют определенные стратиграфические (хронологические) этнокогнитивные топонимические слои в региональной топонимии. К этнокогнитивным относятся топонимы, основанные на определенных типах мировоззрения, выражающие их лингвоментальным способом. Например, некоторые топонимы образуются на основе мифологии. Следовательно, их можно отнести к мифологическим или мифическим этнокогнитивным (мировоззренческим) топонимам. Если мы определяем один тип знания как «историческое знание», в общенациональной или региональной топонимии, то можем рассматривать «исторические топонимы» с позиции соответствия мифологии.

Каждая наука возникает и развивается под влияни- 
ем требований опыта. Топонимия - это область знаний, которая простирается от изучения бытовой лингвистики до области специального образования, в первую очередь из практических потребностей географии. Первые путешественники дали названия вновь открываемым местам и создали названия ранее неизвестных далеких стран и городов, что пошло на благо их народа. Они первыми нанесли на карту новые страны и географические названия. Они были первооткрывателями. Поэтому с первых экспедиций по географической топонимии. Семеновтар-Тянь-Шанский и Л. С. Берг сделалали первые шаги к работе учёных, исследовавших этот вопрос впоследствии.

В лингвистике это понятие изучается по-разному: вопервых, есть мнения В.А. Малышевой и О.Т. Молчанова, И.Н. , во-вторых, можно рассматривать каждый отдельный язык в соотношении к любому схожему. Если оперировать определениями из Оксфордского словаря, то имя собственное, присвоенное определённому месту или объекту, является топонимом [8].

Проблемами общей топонимики занимались российские лингвисты В. Даль, А.В. Суперанская, Л.В. Успенский и др. Различные проблемы топонимической системы Великобритании изучались следующими известными топонимистами:

- профессор английского языка Ливерпульского университета А. Mop (Allen Mawer);

- профессор английского языка Ливерпульского университета, который основал английское топонимическое общество;

- В. Уотс (V. Watts), автор «Кембриджского словаря английских топонимов» [Watts 2004], содержащего названия всех географических объектов Англии, соответствующие комментарии и список наиболее часто используемых топонимических элементов;

- Феллоус-Йенсен (G. Fellows-Jensen), изучавший скандинавские топонимы;

- М. Геллинг (M. Gelling) и А. Коул (A. Cole), занимавшиеся изучением семантики географических терминов древнеанглийского языка;

- К. Кэмерон (K. Cameron) «Dictionary of British toponymy»;

- Э. Эквол (E. Ekwall). Наиболее известные работы: The Place-Names of Lancashire (1922), English PlaceNames in-ing (1923), English River Names (1928), Studies on English Place - and Personal Names (1931), Studies on English Place-Names (1936), Street-names of the City of London (1954), а также монументальный труд сoncise Oxford Dictionary of English PlaceNames (1936);

- П. Рини (Р. Они изучали топонимы» жилище « (habitative) в виде поселений (cot, burh, tun, ham, thorp, by) и искусственного ландшафта;
- . Хоф (C.Hough) и Дж. Джеш (J. Jesch), рассматривавший топонимику английского языка в гендерном аспекте.

В своих исследованиях Р. Коатс изучал особенности топонимов Нормандских островов, графства Гемпшир и Суссекс, а в работе «A new explanation of the name of London 1998)» предложил новую этимологию названия London [9]. АМ. Геллинг занимался изучением топонимии графств Беркшир, Оксфорд и Шропшир [10].

Топономика - одна из частей ономастики, изучающая происхождение, становление (этимология), значение, развитие структуры, ареал распространения, грамматическую, фонетическую форму в современных условиях, письменность и перенос на другом языке. Топонимы, т. е. названия земля-вода, изучаются в основном в трех направлениях:

1. семантика (значение)

2. способы создания

3. этимология

Топонимика развивается во взаимосвязи с данными географии, истории, языкознания, этнологии. Совокупность географических названий любой территории образует топономию изучаемого места. Топонимика считается важным фактором при изучении истории языка. Дело в том, что некоторые топонимы устойчиво сохраняют архаизмы и диалектизмы. Зачастую они дают богатую информацию из субстратных языков населения, населявшего территорию. Особенно важно в данном контексте правильное написание топонимом на языках всех народностей, имевших или имеющих отношение к рассматриваемой территории. Топонимика казахского языка изучалась учеными Г. Конкашбаевым, Н. Баяндиным, А. Абдрахмановым и др.

В результате явления трансонимизации онимы переходят в топонимы и обозначаются терминами антропоним, зоотопоним, фитотопоним, этнотопоним, мифотопоним и др.

В современной лингвистике существует две классификации топонимов:

а) по типу обозначенных географических объектов;

б) по структуре.

По первой классификации выделяют следующие виды топонимов: гидронимы, оронимы, ойконимы, урбанонимы, макротопонимы, микротопонимы и антропотопонимы.

Гидронимы представляют названия водоемов (рек, озер, морей, заливов, проливов, каналов и т.д.) и имеют очень высокую лингво-историческую ценность, так как названия водоемов сохраняются на протяжении веков и 
тысячелетий, в связи с чем претерпевают незначительные изменения. В топонимах (особенно гидронимах) часто встречаются архаизмы и диалектизмы. Они в основном привязаны к субстрату наиболее современных вариаций языка этнических груп рассматриваемой местности. Благодаря анализу гидронимов ученые могут отслеживать этнические и миграционные процессы на прилегающей территории, пути расселения обтателей данной территории и направления миграции. Помимо этого, можно выявлять систематические связи между различными этническими группами и их миграцией, представлять географическое положение местности, исторические события, этнолингвистическое прошлое, этнокультурный фон.

В гидронимах постоянно сохраняются архаизмы и диалектизмы, которые в прошлом часто выходили на языки-субстраты народов, проживающих на прилегающей территории. Это позволяет использовать их для определения границ расселения этнических общностей (например, славян в Европе или финно-угорских народов европейской части России). Пелагонимы - названия морей (Каспийское море, The North Sea, The Irish Sea), лимнонимы - названия озер, прудов (Ала озеро, Балхаш, Loch Tummel, Loch Ney, Llyn CerrigBach), потамонимы названия рек (Сырдарья, Иртыш, Ишим, Severn, Thames, Great Ouse), гелонимы - собственные названия болот (Коргалжын, Алаколь, Сасыкколь. Lindow Moss).

Следующий вид-оронимы (греч. oros-гора), к которым относятся названия гор (Каратау,Ала-тау, The Grampians, Pennines).

Названия небольших поселений делятся ещё на одну группу, которая называется ойконим (греч. oikos-жилье, адрес). К ним относятся деревни (Cuxton, Buttsole, Five Oak Green) и названия городов (Crayford, Earlswood, Great Torrington).

Урбанонимы (лат. urbanonimes, обозначающий названия внутригородских объектов. язык urbanus-городское слово) подразделяется на несколько видов: годонимы (от греч. hodos-дорога, дорога, улица, канал) - названия улиц (улица Абая, улица Тауке хана, Baker Street, Lime Street, Whitehall), агоронимы (греч. agora-площадь) - название площади (площадь Есимхана, Площадь Независимости, Площадь Trafalgar, Piccadilly Circus) и дромонимы (греч. dromos-бег, движение, дорога) - названия путей сообщения (Западный Китай-западноевропейское шосce, Fosse Waylcknield Way, Broxden Roundabout).

Топонимы также подразделяются на макротопонимы (горные хребты, большие впадины, океаны и др.), мезотопонимы (отдельные горы, моря и др.), микротопонимы (озеро, родник, колодец, поселение и др.) Приставки зависят от размеров и площаде рассматриваемых терри- торий. Макротопонимы (от греч. makros-большой) это отдельные названия, обозначающие названия крупных географических объектов. Прежде всего, это названия стран или исторического региона, провинции (Казахстан, England, Russia, Turkey). Макротонимы обычно ассоциируются с этнонимами (Turks - Turkey, Russians Russia, English - England, Bulgarians - Bulgaria, Saxony Saxony). Название страны может происходить от этнонима (Franks-France, Greece-Greece), и наоборот, этнос может образовываться от названия страны (America Americans, Australia - Australians).

К малочисленным объектам или микротопонимам (от греч. к названиям mikros - малый) относятся физико-географические или внутригородские объекты (районы, кварталы и прочие жилые массивы). Обычно они известны только ограниченному кругу лиц, проживающих в определенном районе. Однако некоторые микротопонимы приобретают национальную и даже интернациональную популярность в связи с какими-то событиями. Поэтому иногда достаточно просто упомянуть название населённого пункта (например, Бородино) и сразу же возникает ассоциация с великими событиями. Ещё один пример - Greenham Common (войска Вликобритании боролись с производством и испытанием ядерного оружия, расположенного на военной базе США в Великобритании в городе Greenham Common) [11].

Названия географических объектов часто образуются от личных имен, и в этом случае их называют антропотопонимами (греч. antropos-человек). Например, названия городов: Ottery St Mary St David'S (Уэльс), Elizabethtown, Нур-Султан, Павлодар. Топонимы на английском языке город Buckingham, на казахском языке «народ, племя, люди Букки», имя первого лидера англосаксонцев, захватившего английскую землю, является Buck. Образован от имени этого лидера.

Топонимы по структурной (морфологической) классификации делятся на 4 вида:
а) простые;
б) производные;
в) сложные;
г) составные.

Невозможно назвать число простых топонимов, а составных уж тем более, так что их этимологизация просто невозможна. Тем более, что многие названия перешли из других языков и воспринимаются как чистая основа. Простые непроизводные имена состоят из корневого слова без какого-либо служебного форманта: Comb, Barrow, Down, Stall, Moor и т. д.

Наиболее распространенным типом английских топонимов являются производные. Они образуются путем 
добавления аффиксов к корню морфологической единицы: Stanton, Kingston, Birmingham, Scarborough и др.

К другому типу относятся сложные топонимы. Они состоят из двух морфем, которые выступают в качестве основы топонима: Blackpool, Brentside, Wallingwells, Whitbarrow и др.

Составные топонимы состоят из двух и более фраз: Cold Harbour, Standing Stone, Barton under Needwood, Black Notley и др.

В соответствии с приведенными классификациями любой топоним может быть описан по типу объекта, который он обозначает, в том числе и с точки зрения морфологической структуры.

Различия мировоззрения у разных этнических групп связанео с историческим опытом, накопленными знаниями и прочими особенностями каждой отдельно взятой народности. В связи с этим вполне естественно, что люди разных культур, живущие в одном и том же обществе имеют разные ценности культурного плана. При этом основные различия заключаются в языковом представлении мира и когнитивном сознании каждого индивидуума.

\section{ЛИТЕРАТУРА}

1. Ермолович Д.И. Имена собственные на стыке языков и культур. - М.: Р. Валент, 2001. - 199 с.

2. Щербак А.С., Асанов А.Ю. Принципы построения урбанонимической системы // Вестник Тамбовского университета. - 2015 (а). - №5. - С. $112-117$.

3. Щербак А.С. Когнитивные основы региональной ономастики: монография. - Тамбов, Издательский дом ТГУ им. Г.Р. Державина, 2012. - 319 с.

4. Колшанский Г.В. Объективная картина мира в познании и языке. - М.: Наука, 1990. с. 25.

5. Тилеубердиев Б.М. Лингвокогнитивные аспекты казахской ономастики. - Алматы, Арыс, 2006. - 368 с.

6. Нурашова Г. Отражение проблемы сущности жизни человека в казахской философии. - Алматы, Домино, 2002. - 285 с.

7. Суперанская А.В. Что такое топонимика? - М.: Наука, 1985.

8. Coates R. Toponymic Topics - Essays on the early toponymy of the British Isles.

9. Gelling M. W.F.H. Nicholaisen and M Richards, The Names of Towns and Cities in Britain (1986).

10. Топоров В.Н. Из области теоретической топономастики // ВЯ № 6, 1962.

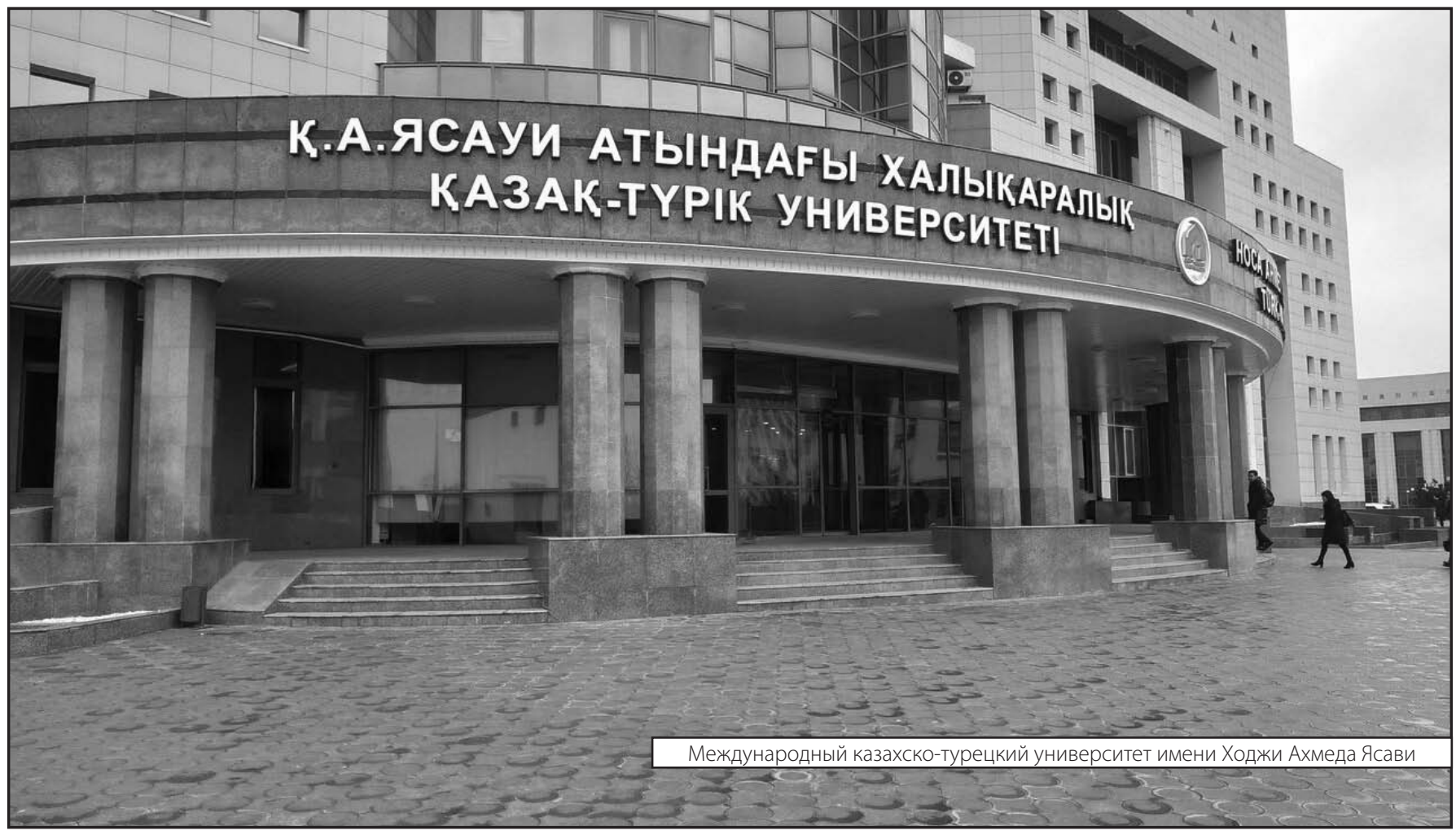

